\title{
Generation of a biotinylatable Sox 2 mouse model to identify Sox 2 complexes in vivo
}

\author{
Kim Schilders • Evelien Eenjes • Gabriëla Edel • Anne Boerema de Munck • \\ Marjon Buscop van Kempen · Jeroen Demmers • René Wijnen • \\ Dick Tibboel $\cdot$ Robbert J. Rottier $\mathbb{D}$
}

Received: 6 September 2017/ Accepted: 19 January 2018/Published online: 30 January 2018

(C) The Author(s) 2018. This article is an open access publication

\begin{abstract}
Sox2 is a Sry-box containing family member of related transcription factors sharing homology in their DNA binding domain. Sox2 is important during different stages of development, and previously we showed that Sox2 plays an important role in branching morphogenesis and epithelial cell differentiation in lung development. The transcriptional activity of Sox 2 depends on its interaction with other proteins, leading to 'complex-specific' DNA binding and transcriptional regulation. In this study, we generated a mouse model containing a biotinylatable-tag targeted at the translational start site of the endogenous Sox2 gene (bioSox2). This tag was biotinylated by the bacterial birA protein and the resulting bioSox 2 protein was used to identify associating partners of Sox 2 at different phases of lung development in vivo (the Sox2 interactome).
\end{abstract}

K. Schilders · E. Eenjes - G. Edel · A. B. de Munck ·

M. B. van Kempen - R. Wijnen - D. Tibboel ·

R. J. Rottier $(\square)$

Department of Pediatric Surgery, Erasmus Medical

Center-Sophia Children's Hospital, Wytemaweg 80,

3015 CN Rotterdam, The Netherlands

e-mail: r.rottier@erasmusmc.nl

\section{J. Demmers}

Netherlands Proteomics Center, Erasmus Medical Center,

Rotterdam, The Netherlands

\section{R. J. Rottier}

Department of Cell Biology, Erasmus Medical Center,

Rotterdam, The Netherlands
Homozygous bioSox 2 mice are viable and fertile irrespective of the biotinylation of the bio tag, indicating that the bioSox 2 gene is normally expressed and the protein is functional in all tissues. This suggests that partners of Sox 2 are most likely able to associate with the bioSox 2 protein. BioSox 2 complexes were isolated with high affinity using streptavidin beads and analysed by MALDI-ToF mass spectrometry analysis. Several of the identified binding partners are already shown to have a respiratory phenotype. Two of these partners, Wdr5 and Tcf3, were validated to confirm their association in Sox2 complexes. This bioSox 2 mouse model will be a valuable tool for isolating in vivo Sox 2 complexes from different tissues.

Keywords Biotinylatable tag · Sox $2 \cdot$ Knock-in · In vivo protein complexes

\section{Introduction}

Sox 2 is a Sry-box containing family member of related transcription factors sharing homology in their DNA binding domain. Sox 2 is highly conserved across species and is involved in several developmental processes (Pevny and Placzek 2005). Sox2 expression is temporally and spatially regulated during development and starts to be expressed at the morula-stage of 
development (Avilion et al. 2003; Liu et al. 2013). Expression becomes restricted to the inner cell mass of the blastocyst and continues in the epiblast, which will give rise to the embryo and germ cells (Avilion et al. 2003). Early during development, expression of Sox 2 is restricted to the anterior ectoderm, from which the neuroectoderm and anterior surface ectoderm will arise (Papanayotou et al. 2008; Wood and Episkopou 1999). At later gestational ages, Sox 2 is expressed in several tissues derived from the primitive foregut endoderm and post-natal it is present in the epithelium of foregut derived organs including the trachea and proximal lung epithelium (Avilion et al. 2003; Donner et al. 2007; Gontan et al. 2008; Ishii et al. 1998; Schlosser and Ahrens 2004; Taranova et al. 2006; Uchikawa et al. 2003). Importantly, together with Oct 4 and Nanog, Sox 2 is part of the core transcription factor network in embryonic stem cells, and Sox 2 is one of the key factors required to induce pluripotent stem cells (iPSC) from in somatic cells (Avilion et al. 2003; Masui et al. 2007; Takahashi et al. 2007; Takahashi and Yamanaka 2006; Yamanaka 2012). Together with Oct4 and Klf4, Sox2 first co-occupies non-permissive chromatin and the subsequent activation of pluripotency-associated genes by Sox 2 (Smith et al. 2016; Xu et al. 2016).

Sox 2 for the induction and generation of Induced Pluripotent Stem Cells is warranted, especially since this transgenic line may be useful for understanding the transition from restricted cell types to reprogramming as pluripotent stem cell, and then the differentiation of these stem cells into specific cell types that retain Sox 2 expression.

We and others have shown that Sox2 plays an important role in lung epithelial cell differentiation and branching morphogenesis (Gontan et al. 2008; Que et al. 2009; Tompkins et al. 2011). In iSox2SPCrtTA mice lung, where Sox 2 expression is induced in the epithelial cells of the developing airways, cystic lesions were observed (Gontan et al. 2008). The size of these cyst-like structures correlated with the timing and duration of ectopic Sox 2 expression (Ochieng et al. 2014). The epithelium of these dilated airway structures had increasing numbers of basal cells and neuroendocrine cells (Gontan et al. 2008). In control lung Sox 2 expression in the epithelial tip cells is inhibited by Fgf10 induced $\beta$-catenin signalling, which prevents these cells to differentiate in proximal epithelial cells (Domyan et al. 2011; Volckaert et al.
2013). Ectopic expression of Sox 2 in these distal epithelial cells aberrantly induced these cells to differentiate into proximal cells, leading to the emergence of basal and neuroendocrine cells. Sox 2 directly activated the $\Delta \mathrm{N}$ Trp63 promoter, indicating that Sox 2 is directly responsible for the emergence of basal cells (Ochieng et al. 2014).

The transcriptional activity of Sox 2 depends on its interaction with other proteins, leading to "complexspecific' DNA binding and transcriptional regulation (Kamachi and Kondoh 2013). Several studies have identified Sox2 associating partners in vitro using different kinds of cells (Ahmed et al. 2012; Boyer et al. 2005; Cox et al. 2010; Cox et al. 2013; Donner et al. 2007; Engelen et al. 2011; Fang et al. 2011; Inoue et al. 2007; Kamachi et al. 2001; Kondoh and Kamachi 2010). One of the partners identified in neural stem cells is Chd7. Sox 2 and Chd7 cooperate to regulate genes involved in human syndromes that are genetically unrelated but do show a similarity in symptoms (Engelen et al. 2011). By performing large scale immunoprecipitations in stable FLAG/Sox 2 transgene embryonic stem (ES) cells, several partners were identified including ES cell self-renewal factors and several lineage-specific transcription factors. Also, $\mathrm{Xpo} 4$ was identified as a Sox 2 partner, functioning as a nuclear import receptor for Sox2 (Gontan et al. 2009).

Processes in which Sox 2 is involved in lung development could be the influenced by specific interaction partners and therefore in vivo binding partners of Sox 2 were identified in this study, using a mouse model containing a biotinylated Sox 2 (bioSox2). The biotinylated Sox 2 was efficiently isolated, including associating protein complexes due to the very high affinity of the biotin-streptavidin interaction, which is several magnitudes higher than antibodyantigen interactions (de Boer et al. 2003).

BioSox 2 containing complexes were efficiently isolated from mouse embryonic day 18.5 lungs and brains using streptavidin and subsequently analysed by mass spectrometry. We identified a number of putative binding partners involved in lung development, such as Akap8, Ank3, Dkc1, Cavin (Ptrf) and Safb1. 


\section{Materials and methods}

Generation of bioSox2/birA mice

To generate an N-terminal biotin-tagged Sox2 allele (bioSox2), Sox2 genomic DNA was isolated from library with 129 genomic DNA and a NheI-Asp718 fragment containing the Sox2 exon was used to generate the recombination construct used for targeting IB10 ES cells. Genomic DNA of individual clones was digested with EcoRI and screened with specific probes. The neomycin resistance gene was removed from positive clones by transiently expressing Cre in ES cells, and individual clones were genotyped and karyotyped before injection in blastocysts. Chimaeric mice were crossed and maintained on C57/bl6 background. BioSox 2 mice were crossed with birA mice to biotinylate the biotag. Mice were kept under standard conditions and experiments were performed following guidelines of the ethics committee of the Erasmus Medical Center.

Large scale tissue immunoprecipitations

Lungs and brains were isolated from bioSox $2 /$ birA and birA mice E18. Tissues were minced into small pieces and a single cell solution was prepared using a cell strainer. Immunoprecipitations were essentially done as previously published (Engelen et al. 2011; Gontan et al. 2009). Cells were lysed in cell lysis buffer (10 mM Hepes 7.6, $1.5 \mathrm{mM} \mathrm{MgCl} 2,10 \mathrm{mM} \mathrm{KCl}$; add $0.5 \mathrm{mM}$ DTT + protease inhibitors prior to use), followed by lysis of the nuclei in nuclei lysis buffer (20 mM Hepes pH 7.6, 20\% glycerol, $420 \mathrm{mM} \mathrm{NaCl}$, $1.5 \mathrm{mM} \mathrm{MgCl} 2,0.2 \mathrm{mM}$ EDTA, add $0.5 \mathrm{mM}$ DTT $+1 \times$ CEF prior to use). Nuclear extracts were diluted $1: 1$ in low-salt buffer (20 mM Hepes pH7.6, $20 \%$ glycerol, $1.5 \mathrm{mM} \mathrm{MgCl}_{2}, 0.2 \mathrm{mM}$ EDTA) and incubated with $40 \mu \mathrm{l}$ Dynabeads ${ }^{\circledR} \mathrm{M}-280$ Streptavidin (Cat. No. $112.06 \mathrm{D}$, Invitrogen) for at least $1 \mathrm{~h}$ rotating at $4{ }^{\circ} \mathrm{C}$ in non-stick tubes. After washing with wash buffer (20 mM Hepes pH7.6, 20\% glycerol, $100 \mathrm{mM} \mathrm{KCl}, 1.5 \mathrm{mM} \mathrm{MgCl}_{2}, 0.2 \mathrm{mM}$ EDTA, $0.02 \%$ $\mathrm{NP}-40$; add $1 \times \mathrm{CEF}$ prior to use), the beads were resuspended in $40 \mu \mathrm{l}$ sample buffer $(60 \mathrm{mM}$ Tris- $\mathrm{HCl}$ $\mathrm{pH} 6.8,2 \%$ SDS, $0.02 \%$ bromophenol blue, $10 \%$ glycerol, $1 \% \beta$-mercaptoethanol, $5 \mathrm{mM}$ DTT) and heated for $10 \mathrm{~min}$ at $95^{\circ} \mathrm{C}$. Samples were loaded on pre-cast gel and sent to the department of
Biochemistry for Matrix Assisted Laser Desorption/ Ionization-Time of Flight Mass Spectrometry (MALDI-TOF MS) analysis.

BioSox 2 immunoprecipitation in transfected HEK cells

HEK cells were cultured in DMEM (Lonza, Verviers, Belgium) with $5 \%$ fetal calf serum and $1 \%$ penicillinstreptomycin under standard culture conditions. Cells were transfected with a N-terminal tagged bioTEVSox 2 and birA expression constructs using Lipofectamine-2000 (Invitrogen) according to the manufacturer's manual. Cells were harvested $24 \mathrm{~h}$ after transfection and nuclear extracts were prepared by lysing the cells with cell lysis buffer, followed by nuclei lysis buffer. Nuclear extracts were diluted 1:1 in low-salt buffer and incubated with Dynabeads ${ }^{\circledR} \mathrm{M}-280$ Streptavidin for at least $1 \mathrm{~h}$ rotating at $4{ }^{\circ} \mathrm{C}$ in nonstick tubes. After washing with wash buffer, the beads were resuspended in $40 \mu \mathrm{l}$ sample buffer and heated for $10 \mathrm{~min}$ at $95{ }^{\circ} \mathrm{C}$. Mock-transfected HEK cells were used as a control.

Co-transfections and co-immunoprecipitations

HEK cells were transfected with either a myc-tagged TCF3 expression construct (Pereira et al. 2006), together with 2xFLAGbio-Sox2, or with a FLAGtagged WDR5 construct (Lee and Skalnik 2005), together with myc-Sox2. X-tremeGENE HP DNA Transfection Reagent (Roche, Basel, Switzerland) was used for the transfection according to the manufacturer's manual. ${ }^{[6]}$ Cells were harvested $24 \mathrm{~h}$ after transfection. Total cell extracts were prepared in $300 \mu$ carin buffer $(20 \mathrm{mM}$ Tris pH8, $137 \mathrm{mM} \mathrm{NaCl}$, 10 mM EDTA, 1\% NP40, 10\% glycerol) with Complete protease inhibitor (Roche, Basel, Switzerland). $50 \mu \mathrm{l}$ was incubated for $2 \mathrm{~h}$ at $4{ }^{\circ} \mathrm{C}$ in $250 \mu \mathrm{l}$ carin buffer with antibodies against myc (1668149, Roche) and FLAG (F1804), followed by $1 \mathrm{~h}$ incubation with protein $\mathrm{G}$ beads (Sigma-Aldrich, St. Louis, MO). After washing with carin buffer, the beads were resuspended in $20 \mu \mathrm{l}$ sample buffer and heated for $10 \mathrm{~min}$ at $95^{\circ} \mathrm{C}$. 


\section{Results}

Generation of bioSox 2 mice

Sox 2 associating proteins have mostly been identified using a tagged Sox 2 protein expressed in different cell lines (Cox et al. 2010, 2013; Engelen et al. 2011; Fang et al. 2011). In vitro cell culture models lack the microenvironment of cells in vivo, which could result in aberrant expression patterns and therefore a difference in partners in vitro and in vivo. Since the expression of Sox 2 is temporally and spatially regulated, it is expected that there is also a dynamic change in interaction partners during the different stages of gestation. In order to isolate and identify in vivo Sox 2 complexes with high specificity, we generated a mouse line expressing Sox 2 with a small artificial peptide tag of seventeen amino acids (biotag) at the $\mathrm{N}$-terminus. This biotag can be biotinylated in vivo by a biotin ligase protein (birA) and the protein can subsequently be isolated with high affinity using streptavidin (de Boer et al. 2003). As a proof of principle, the functionality of the biotinylated Sox 2 protein was tested in vitro by co-expressing the $\mathrm{N}$-terminal bio-tagged Sox 2 with the bacterial birA biotin ligase. Previously, we showed that a N-terminal FLAG-tagged Sox2 protein was fully functional (Engelen et al. 2011; Gontan et al. 2009). The biotag was efficiently biotinylated by birA, as shown by western blot and by streptavidin specific precipitation of the biotinylated Sox2 from nuclear extracts (Fig. 1a). Moreover, the biotinylated Sox 2 was able to bind to the Sox 2 consensus binding site in vitro by an electrophoretic mobility shift assay (data not shown). We also tested the Tobacco Etch Virus (TEV) protease cleavage site, which was introduced after the biotag to facilitate the recovery of streptavidin precipitated bioSox 2 from the magnetic streptavidin beads for subsequent analysis. BioSox 2 and associating factors were purified from nuclear extracts of bioSox $2 /$ birA transfected HEK cells using magnetic streptavidin beads and precipitated proteins were released either by incubation with the TEV protease or by heating the beads for ten minutes. Western blot analysis showed that the TEV protease recognized and processed the bioSox 2 protein, but unfortunately the cleaved Sox 2 did not elute from the beads (Fig. 1b). Since the level of Sox 2 is important, we decided to design a fragment of the Sox 2 locus with the bio-tag to specifically target the endogenous locus by homologous recombination (Fig. 1c).

Therefore, a $11 \mathrm{~kb}$ NheI-Asp718 genomic fragment of 129 mouse DNA containing the Sox 2 exon $(-4123$ till +7221 , TS is position 1) was isolated. A fragment containing a Neomycin resistance gene (Neo) driven by the HSV-tk promoter and flanked by loxP sites was inserted in the SpeI site upstream the Sox2 exon $(-478)$, the site which has previously been used to construct Sox 2 mutant mice (Taranova et al. 2006). With this fragment, an additional EcoRI site was created. Downstream of the Sox 2 encoding region, in the SphI site (2445, counted from TS), a loxP site was introduced, also containing an EcoRI site. Finally, an oligonucleotide with the sequence coding for the 17 amino acid biotag and a TEV endoprotease cleavage site was inserted between the first and second amino acid encoding sequence of the Sox 2 gene $(+362)$. Thus, the translation initiates at the endogenous ATG and results in an in-frame insertion of the biotag leading to a fusion protein (bio-TEV-Sox2). The biotag can be biotinylated at a specific lysine residue by the bacterial birA ligase, as previously shown (de Boer et al. 2003). Homologous recombination was performed in 129/Ola derived IB10 ES cells, and subsequent isolated Neomycin resistant clones were analysed by Southern blotting (Fig. 1d). One of the ES clones that had the correct integration and the correct karyotype was subsequently used to transiently express Cre recombinase to remove the Neo cassette. After the removal of the cassette, the ES clone was injected into blastocysts and transferred to pseudopregnant females. The resulting mouse line contained the biotag in frame in the Sox 2 coding sequence (see Fig. 1e), as well as loxP sites around the Sox 2 exon, which may be used to genetically ablate the Sox 2 gene. The mice that contained the correct targeted Sox 2 locus (bioSox 2 mice) were subsequently crossed with a mouse line ubiquitously expressing a HAtagged birA from the ROSA26 locus to generate bioSox 2/birA mice (Driegen et al. 2005).

Homozygous bioSox 2 mice, with or without the biotin ligated to the $\mathrm{N}$-terminal tag, were born at Mendelian ratios, were viable and fertile. However, the targeted locus may interfere with the pattern of expression, thus we first compared the expression pattern of the biotinylated Sox 2 with the endogenous, untagged Sox2. Several tissues were isolated from adult mice that either had the bioSox 2 allele 
A

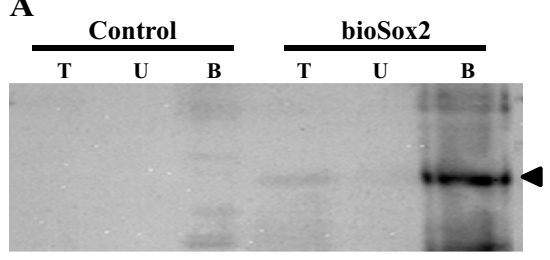

C
B

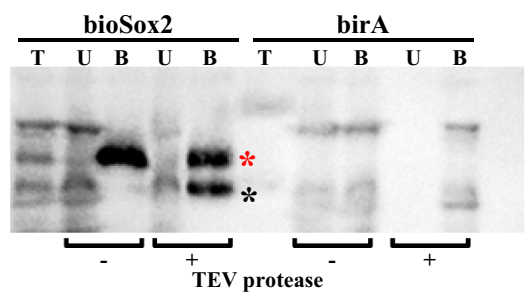

WT Sox2 locus

15 kb

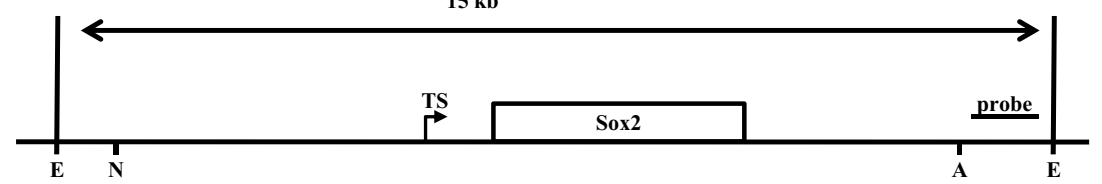

bioSox2 locus

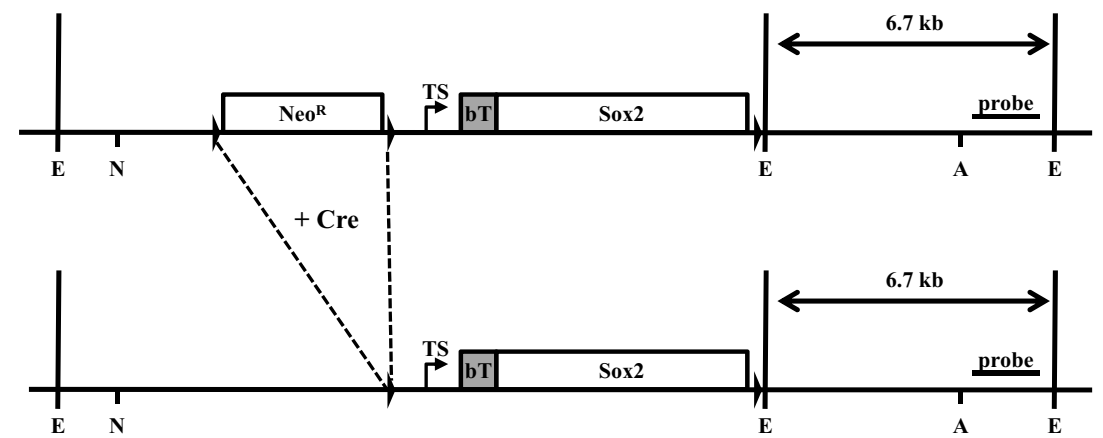

D

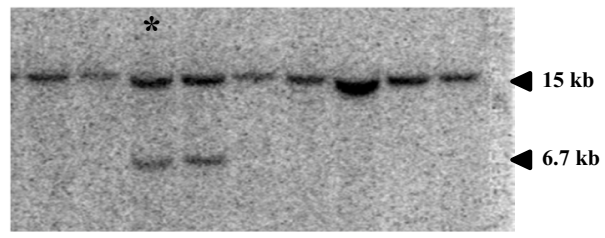

$\mathbf{E}$

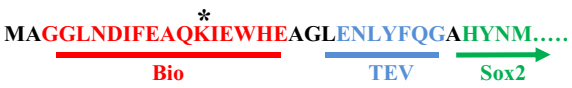

Fig. 1 Development of biotin tagged Sox2 locus. a Nuclear extracts of transiently transfected HEK cells with control vector (control) or expression constructs for birA and bioSox 2 (bioSox2) were incubated with streptavidin coupled dynabeads. Total input $(T)$, unbound fraction $(U)$ and the streptavidin bound fraction $(B)$ analyzed on western blot using HRP coupled streptavidin. Arrow indicates the purified $40 \mathrm{kDa}$ biotinylated Sox 2 protein. b Identical experiment as in a, except that the purified samples were incubated with or without TEV protease. Although the bioSox 2 was cleaved by the TEV, the protein remained attached to the beads. $\mathrm{T}$ is a fraction of the total input material before the beads were added to the extract. $U$ represents the unbound fraction eluted from the beads after incubation with the TEV protease, whereas $B$ represents the bound fraction, which was left on the beads after the TEV protease incubation. The $B$ fraction was subsequently retrieved by boiling the beads. c Construct design to modify the Sox 2 locus by homologous recombination. The Neomycin cassette was introduced upstream the transcriptional start site (TS), flanked by two loxP sites (arrow heads). The restriction sites used to isolate the fragment used to electroporate ES cells are indicated (N: NheI; A: Asp718), as well as the EcoRI sites $(E)$ to analyze genomic DNA with the $3^{\prime}$ probe. d Representative Southern blot of ES genomic DNA digested with EcoRI and probed with the indicated $3^{\prime}$ probe, resulting in the wild type band at $15709 \mathrm{bp}$, and a mutant band 6771. e Schematic overview of the bioTEVSox 2 protein and the $\mathrm{N}$-terminal amino acids representing the translational start of the Sox 2 protein (MA) followed by the Bio tag, a short hinge region (AGL) and the TEV protease cleavage recognition site (TEV). The asterisk indicates the lysine residue that is biotinylated by the BirA protein 
(bioSox2), carried the HA-BirA transgene (birA), or were double positive for the bioSox 2 allele and the HA-BirA transgene (bioSox2/birA). Immunohistochemistry using an antibody against Sox 2 or HRPconjugated streptavidin showed that expression pattern of the bioSox 2 in the esophagus and lung is similar to the endogenous Sox 2 expression (Fig. 2a). the expression of the biotinylated Sox 2 protein was identical to the control Sox2, as shown for lung and trachea (Fig. 2a). Next, we evaluated the level of transcription by isolating nuclear extracts of embryonic brains at gestational age 17.5. Subsequent western blot analysis showed that the bioSox2 (40 kDa) was equally expressed as the endogenous Sox2 (34 kDa; Fig. 2b). This provided evidence that the targeting itself did not interfere with the transcriptional and translational machinery.

Thus, the expression of the tagged bioSox 2 was comparable to normal, untagged Sox2, and the bioSox 2 was efficiently biotinylated in vivo by the
birA protein. Collectively, this indicated that the bioSox 2 gene is normally expressed and the tagged protein is fully functional in all tissues. It also implies that all the partners of Sox 2 are still able to associate with bioSox 2 and fulfill their biological roles, since the absence of correct complex formation will lead to lethal phenotypes.

\section{BioSox2 affinity-purification}

As a proof of principle, Sox 2 complexes were isolated from fetal trachea and lung tissue isolated just prior to birth. At this phase of development, the epithelium of the trachea and upper airways consists of Sox2 positive cells, so total lungs were isolated at day 18.5 of gestation of bioSox2/HA-birA and HA-birA pups. Nuclear extracts were prepared and bioSox 2 complexes were purified with streptavidin-coupled magnetic beads. The bioSox 2 purification was performed in triplicate and the precipitation was first
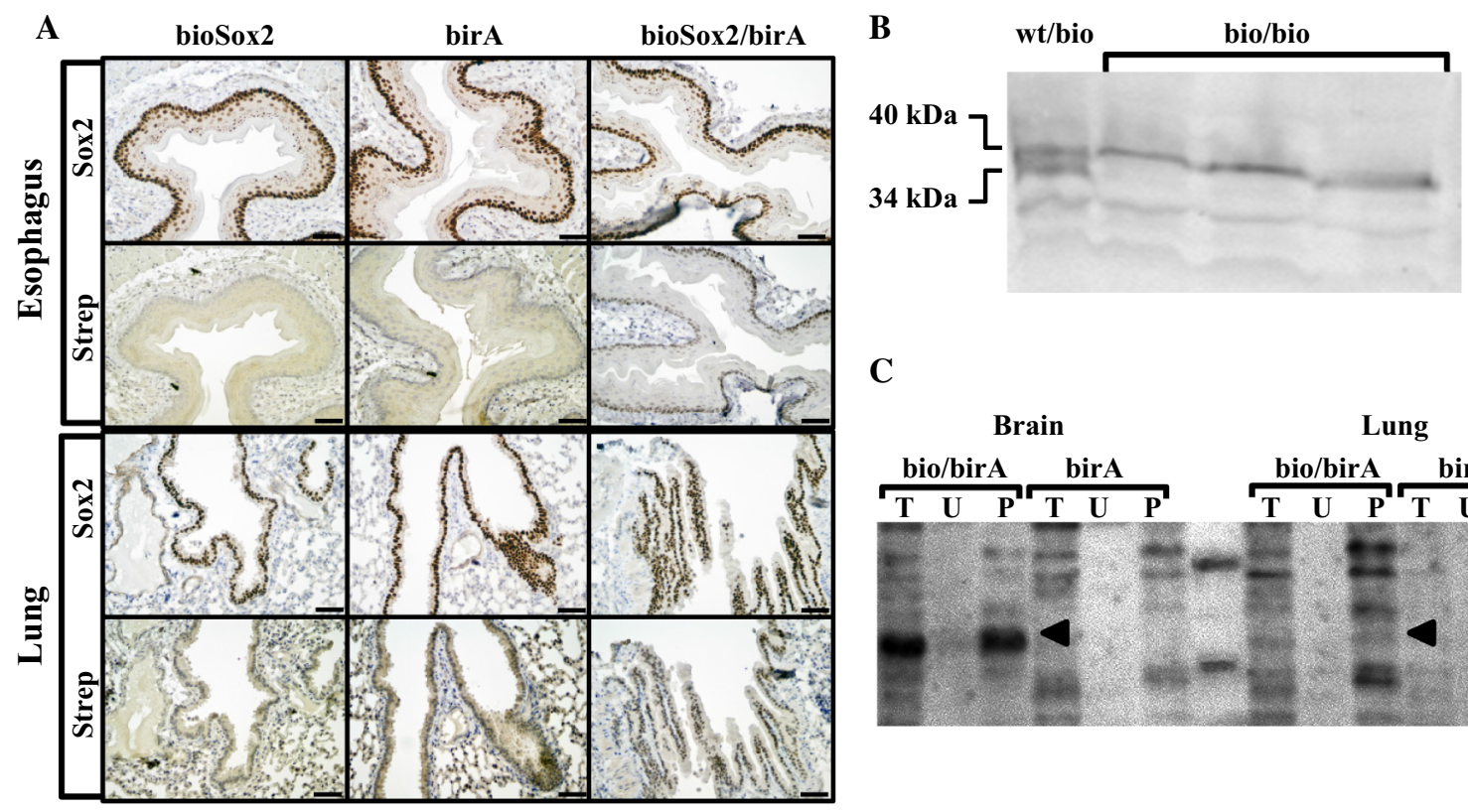

C

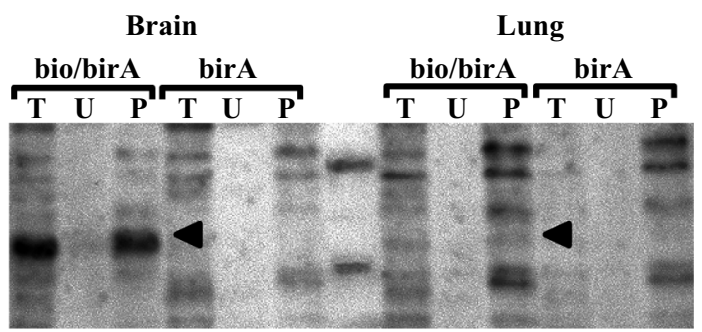

Fig. 2 Functional analysis of the bioSox 2 mouse. a Immunohistochemistry analysis of esophagus and lungs of adult bioSox 2 , birA and bioSox2/birA mice showing the expression of Sox 2 using an antibody against Sox 2 protein (Sox2). Using HRP coupled streptavidin (Strep) shows that the biotinylated Sox 2 is expressed in the same cells as the normal Sox2. Moreover, biotinylation only occurs in the mice that carries the bioSox 2 allele and the birA transgene. b Total protein extracts isolated from $\mathrm{E} 17.5$ brains of heterozygous Sox $2 /$ bioSox 2 mice (wt/bio) and homozygous bioSox 2 mice (bio/bio) were analyzed by western blot analysis using a Sox 2 antibody. This showed that the expression of the Sox $2(34 \mathrm{kDa})$ and bioSox $2(40 \mathrm{kDa})$ are comparable (lane wt/bio). c In vivo purification of bioSox 2 from nuclear extracts of brain and lung tissue isolated at E18 from bioSox $2 /$ birA (bio/birA) and birA only (birA) mice using dynabeads. Arrowheads indicate the band representing the bioSox2, showing specific purification of the bioSox 2 in the bioSox $2 /$ birA extracts. The western blot is labeled with streptavidine coupled HRP. Indicate lanes are total input $(T)$, unbound fraction $(U)$ and the purified fraction $(P)$ 
evaluated, indicating that the bioSox 2 was efficiently purified from the bioSox $2 /$ birA mouse samples compared to the control birA only samples (Fig. 2c; arrowheads). It also showed that the bioSox 2 protein was less prominently present in the lung samples, as expected, since Sox2 is expressed in a subset of epithelial cells.

The total precipitated proteins were separated on a polyacrylamide gel, which was stained with Coomassie Brilliant Blue and analyzed by MALDI-TOF MS. Comparing the three independent immunoprecipitations, 114 unique proteins were identified with a similar accession code and a mascot score above 80 that were enriched in the lung, while in the brain 28 unique proteins were found. Enrichment was determined by subtracting the number of unique proteins in the birA samples from the number of unique proteins in the bioSox 2/birA samples. Aside from the identification of several potential binding partners that we previously described in epitope-tagged Sox 2 pull down experiments performed with lysates from mouse embryonic stem cells and mouse neural stem cells (Engelen et al. 2011; Gontan et al. 2009), we found a number of potential partners that were linked to respiratory phenotypes in mice when ablated, including Akap8, Ank3, Dkc1, Cavin (Ptrf) and Safb1 (Fig. 3a).

Wdr5 and Tcf3 are binding partners of Sox 2

Putative binding partners were selected on the basis of their Mascot scores and the number of peptides retrieved in the mass spectrometry analysis. This set of proteins was subsequently analyzed for known cellular functions and their potential role in lung development, which resulted in a short list of putative Sox 2 interacting proteins. To validate our results, we selected the WD repeat domain 5 (Wdr5) and Transcription factor 3 (Tcf3) proteins, since $\mathrm{Wdr} 5$ was described as a potential Sox 2 binding partner in ES cells and we previously identified Tcf 3 as a putative Sox 2 binding protein in neural stem cells (Ang et al. 2011; Engelen et al. 2011).

Next, HEK cells were transiently transfected with expression constructs of a FLAG-tagged Sox 2 and a myc-tagged Tcf3, or a myc-tagged Sox 2 with a FLAG/ HA-tagged Wdr5 to analyze their physical interaction. Extracts of transfected cells were incubated with the appropriate antibodies to immunoprecipitate the tagged Sox 2 or Tcf3/Wdr5 and co-precipitated proteins were analyzed. We first analysed whether we could detect the interaction between Sox 2 and one of its known partners, Wdr5. Immunoprecipitation of FLAG-Wdr5 with a FLAG antibody efficiently coprecipitated the myc-Sox 2 protein as indicated by the myc positive signal (Fig. 3b). In the reverse experiment, immunoprecipitation of myc-Sox 2 with a myc antibody showed co-precipitation the FLAG-Wdr5 protein with the FLAG antibody. Next, we analysed whether the putative partner, Tcf3, could also be coprecipitated with Sox2. Indeed, the FLAG-Sox2 efficiently associated with myc-Tcf3 as shown by the FLAG and myc specific precipitations (Fig. 3c). Thus, our data showed that aside from $\mathrm{Wdr} 5$, we identified Tcf3 as a specific partner of Sox 2 .

\section{Discussion}

Several studies have identified Sox 2 interaction partners in vitro using different approaches (Cox et al. 2010, 2013; Engelen et al. 2011; Fang et al. 2011). To gain more knowledge about the role of Sox2-partner complexes in vivo, we developed a mouse model expressing a biotinylatable Sox 2 protein. As a proof of principle, we have efficiently purified the tagged Sox 2 protein using streptavidin in a single-step approach using fetal lung.

The mass spectrometry data of the three large scale immunoprecipitations resulted in low scores of the bait, the bioSox 2 . This is partially due to the unfavourable distribution of the tryptic cleavage sites in the Sox 2 protein and the presence of acidic amino acids within some of its peptides. Also, there is a low number of Sox $2^{+}$cells in the lung $(\sim 10 \%)$ compared to the brain where the bait-Sox 2 score is much higher (not shown), showing that the assay itself works very efficiently. To obtain higher mascot scores and enrichment, we repeated the IP with a more protein as input. This resulted in a better enrichment of Sox 2 .

Tcf3 and Wdr5 were used to validate physical interaction with Sox2. Tcf3 was also previously identified as a potential Sox 2 partner in a large scale purification assay in neural stem cells (Engelen et al. 2011). Tcf3 is involved in anterior-posterior axis induction during early embryonic development. $\mathrm{Tcf}^{-1-}$ mice showed an expansion and duplication in the axial mesoderm (Merrill et al. 2004). Tcf3 is 
Fig. 3 In vivo isolation of bioSox 2 complexes. a Large scale purification of bioSox 2 complexes from E18.5 lungs revealed several putative Sox 2 associating proteins. The expression pattern of some of these partners is represented (genepaint). b, c Physical interaction between Wdr5 (b) and Tcf3 (c) with Sox 2 was confirmed in co-immunoprecipitations. The myc antibody precipitated the myc-Sox2 (b) or myc-Tcf3 (c), and coprecipitated the FLAG tagged Wdr5 (b) or Sox 2 (c). These interactions were confirmed by performing the reciprocal imunoprecipitations

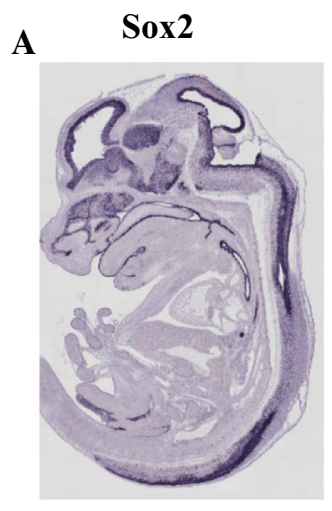

Hbb-b1

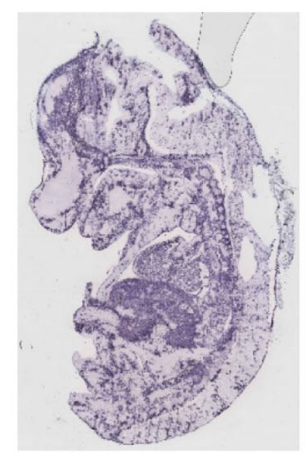

B

Sox 2

C

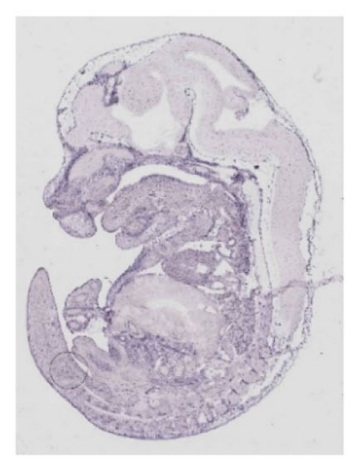

Ank3

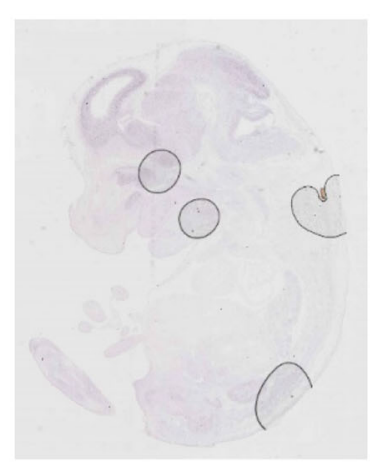

Ptrf

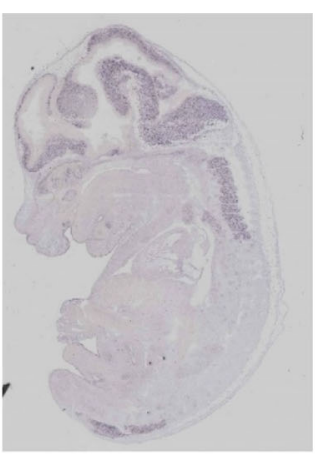

Akap8

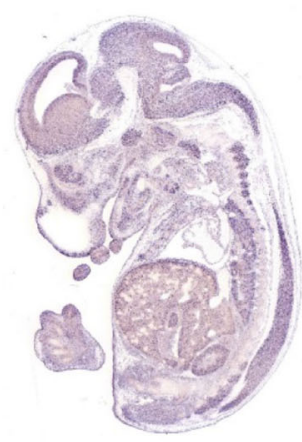

Sox2
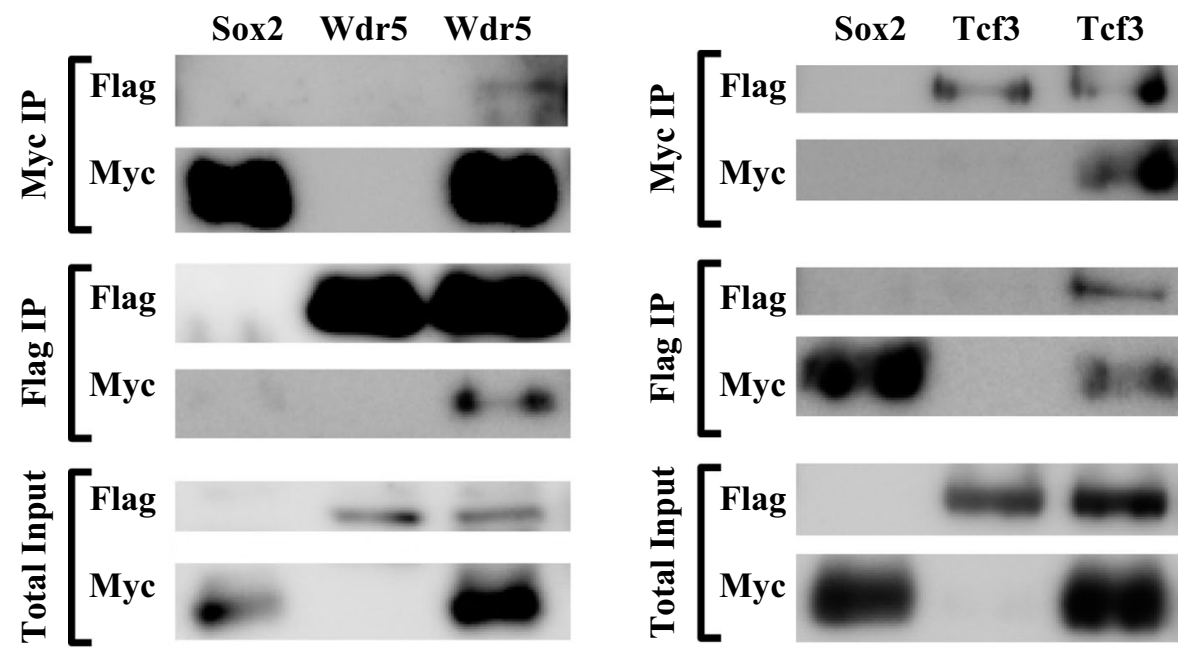

also involved in stem cell renewal, by inhibiting a subset of genes which results in repression of selfrenewal (Yi et al. 2011). Tcf3 is expressed in skin epithelial cells and overexpression results in repression of epithelial cell differentiation (Merrill et al. 2001; Nguyen et al. 2006). Genetic ablation of the
Tcf3- $\beta$ catenin interaction showed that this interaction is not required before gastrulation, but later during development in several crucial processes, such as vascular integrity and neural tube closure (Wu et al. 2012). It also showed that $\beta$ catenin relieves Tcf3 repression of Lef1, and subsequently activate Wnt 
target genes through its interaction with Lef1 (Wu et al. 2012). The antagonistic effect of Wnt signaling and Tcf3 expression was also confirmed in ES cells (Atlasi et al. 2013; Yi et al. 2011).

$\mathrm{Wdr} 5$ is involved in several processes including cell cycle progression and gene regulation. It interacts with Hdac3 under hypoxic conditions and then induces mesenchymal gene expression (Wu et al. 2011). As such, it plays a crucial role in hypoxia-induced epithelial-mesenchymal transition, which is important in processes as organ development and fibrosis. Wdr5 is also a direct target of Sry, as well as an interaction partner, and the Wdr5-Sry complex activates Sox9 and represses $\beta$-catenin expression in sex determination (Xu et al. 2012). In embryonic stem cells, Wdr5 is identified as a regulator of embryonic stem cell renewal. In these cells, Wdr5 is a direct binding partner of Oct 4 and it has been shown that they have an overlap in gene regulatory functions. Immunoprecipitations done in the same study, also suggested interaction between Sox 2 and Wdr5 (Ang et al. 2011). Co-immunoprecipitations that we performed validated this interaction. Wdr5 was also enriched in our first large scale bioSox 2 immunoprecipitation in both the lung and trachea, suggesting that the Wdr5Sox 2 protein complex can be involved in lung development.

Several of the potential partners identified in the lung tissue IP can be linked to a respiratory phenotype in mice. Akap 8 (AKAP95), a member of the A-kinase anchor protein family, is a scaffold protein. Akap8 is together with fidgetin critical for palatogenesis in mice. Mice with only Akap8 mutations do not show any abnormalities, but mice with both Akap8 and fidgetin deficiencies show symptoms of respiratory distress and die due to cleft palate (Yang et al. 2006). Ankyrin 3 (Ank3/Ankyrin G) is a protein that is linked to integral membrane proteins. In bronchial epithelial cells, Ankyrin G is necessary for the biogenesis and preservation of the lateral membrane (Kizhatil and Bennett 2004; Kizhatil et al. 2007). Ank3 mutant mice show abnormal bronchus epithelium morphology (Jenkins et al. 2013). Dyskerin (DKC1) is linked to dyskeratosis congenital, which is characterized by premature aging and a higher tumor susceptibility. Patients suffering from this disease also display interstitial lung fibrosis. Hypomorphic Dkc1 mutant mice show lung abnormalities, including abnormal morphology of the pulmonary parenchyma, alveolus and alveolus wall, lung inflammation and pulmonary interstitial fibrosis (Ruggero et al. 2003). Cavin1 (Ptrf) is a protein that is involved in the regulation of rRNA transcription. Deletion of Cavin1 results in loss of caveolae in the lung, increased density of lung tissue and elevated pulmonary arterial pressure (Sward et al. 2013). Deletion of Cavin2 results in loss of endothelial caveolae in lung tissue (Hansen et al. 2013). Ptrf abnormal lung morphology and abnormal vasculature morphology. Scaffold attachment factor B1 (Safb1) is involved in development, growth and reproduction. abnormal lung alveolus development and Safb1 $1^{-1-}$ mice show defects in lung maturation resulting in abnormal development of the alveoli (Ivanova et al. 2005). Similarities in the expression pattern of Sox 2 and these potential partners at E14.5 can be found in supplementary data 1 (Genepaint, Visel et al. 2004).

In conclusion, we generated a mouse model containing a biotinylatable-tag targeted at the translational start site of the endogenous Sox 2 gene. BioSox 2 containing complexes can efficiently be isolated from various Sox 2 expressing tissues and cell types using the mouse model.

Acknowledgements We would like to thank Dr. David Skalnik for the Wdr5 construct, Dr. Brad Merrill for the Tcf3 construct and Prof. Dies Meijer and Dr. Martine Jaegle for the HA-birA mice. Furthermore, we would like to thank Dr. Raymond Poot for his initial help by analyzing the proteomics data and Dr. Cristina Gontan for starting the initial cloning of the bioSox 2 targeting construct.

Funding This study was funded by SSWO (Grant Number $641 \mathrm{KS}$; and Grant Number S14-12 EE).

\section{Compliance with ethical standards}

Conflict of interest The authors declare that they have no conflict of interest.

Open Access This article is distributed under the terms of the Creative Commons Attribution 4.0 International License (http:// creativecommons.org/licenses/by/4.0/), which permits unrestricted use, distribution, and reproduction in any medium, provided you give appropriate credit to the original author(s) and the source, provide a link to the Creative Commons license, and indicate if changes were made.

\section{References}

Ahmed M, Xu JS, Xu PX (2012) EYA1 and SIX1 drive the neuronal developmental program in cooperation with the SWI/SNF chromatin-remodeling complex and Sox 2 in the 
mammalian inner ear. Development 139:1965-1977. https://doi.org/10.1242/dev.071670

Ang YS et al (2011) Wdr5 mediates self-renewal and reprogramming via the embryonic stem cell core transcriptional network. Cell 145:183-197. https://doi.org/10.1016/j.cell. 2011.03.003

Atlasi Y et al (2013) Wnt signaling regulates the lineage differentiation potential of mouse embryonic stem cells through Tcf3 down-regulation. PLoS Genet 9:e1003424. https://doi.org/10.1371/journal.pgen.1003424

Avilion AA, Nicolis SK, Pevny LH, Perez L, Vivian N, LovellBadge R (2003) Multipotent cell lineages in early mouse development depend on Sox2 function. Genes Dev 17:126-140. https://doi.org/10.1101/gad.224503

Boyer LA et al (2005) Core transcriptional regulatory circuitry in human embryonic stem cells. Cell 122:947-956. https:// doi.org/10.1016/j.cell.2005.08.020

Cox JL, Mallanna SK, Luo X, Rizzino A (2010) Sox2 uses multiple domains to associate with proteins present in Sox2-protein complexes. PLoS ONE. https://doi.org/10. 1371/journal.pone.0015486

Cox JL, Wilder PJ, Gilmore JM, Wuebben EL, Washburn MP, Rizzino A (2013) The Sox2-interactome in brain cancer cells identifies the requirement of MSI2 and USP9X for the growth of brain tumor cells. PLoS ONE. https://doi.org/10. 1371/journal.pone.0062857

de Boer E et al (2003) Efficient biotinylation and single-step purification of tagged transcription factors in mammalian cells and transgenic mice. Proc Natl Acad Sci USA 100:7480-7485

Domyan ET, Ferretti E, Throckmorton K, Mishina Y, Nicolis SK, Sun X (2011) Signaling through BMP receptors promotes respiratory identity in the foregut via repression of Sox2. Development 138:971-981. https://doi.org/10.1242/ dev.053694

Donner AL, Episkopou V, Maas RL (2007) Sox2 and Pou2f1 interact to control lens and olfactory placode development. Dev Biol 303:784-799

Driegen S et al (2005) A generic tool for biotinylation of tagged proteins in transgenic mice. Transgenic Res 14:477-482. https://doi.org/10.1007/s11248-005-7220-2

Engelen E et al (2011) Sox 2 cooperates with Chd7 to regulate genes that are mutated in human syndromes. Nat Genet 43:607-U153. https://doi.org/10.1038/Ng.825

Fang XF et al (2011) Landscape of the Sox2 protein-protein interactome. Proteomics 11:921-934. https://doi.org/10. 1002/pmic.201000419

Gontan C, de Munck A, Vermeij M, Grosveld F, Tibboel D, Rottier R (2008) Sox2 is important for two crucial processes in lung development: branching morphogenesis and epithelial cell differentiation. Dev Biol 317:296-309

Gontan C et al (2009) Exportin 4 mediates a novel nuclear import pathway for Sox family transcription factors. J Cell Biol 185:27-34. https://doi.org/10.1083/jcb.200810106

Hansen CG, Shvets E, Howard G, Riento K, Nichols BJ (2013) Deletion of cavin genes reveals tissue-specific mechanisms for morphogenesis of endothelial caveolae. Nat Commun 4:1831. https://doi.org/10.1038/ncomms2808

Inoue M, Kamachi Y, Matsunami H, Imada K, Uchikawa M, Kondoh H (2007) PAX6 and Sox2-dependent regulation of the Sox2 enhancer N-3 involved in embryonic visual system development. Genes Cells 12:1049-1061. https:// doi.org/10.1111/j.1365-2443.2007.01114.x

Ishii Y, Rex M, Scotting PJ, Yasugi S (1998) Region-specific expression of chicken Sox 2 in the developing gut and lung epithelium: regulation by epithelial-mesenchymal interactions. Dev Dyn 213:464-475

Ivanova M et al (2005) Scaffold attachment factor B1 functions in development, growth, and reproduction. Mol Cell Biol 25:2995-3006. https://doi.org/10.1128/MCB.25.8.29953006.2005

Jenkins PM, Vasavda C, Hostettler J, Davis JQ, Abdi K, Bennett $\mathrm{V}$ (2013) E-cadherin polarity is determined by a multifunction motif mediating lateral membrane retention through ankyrin-G and apical-lateral transcytosis through clathrin. J Biol Chem 288:14018-14031. https://doi.org/ 10.1074/jbc.M113.454439

Kamachi Y, Kondoh H (2013) Sox proteins: regulators of cell fate specification and differentiation Development 140:4129-4144. https://doi.org/10.1242/dev.091793

Kamachi Y, Uchikawa M, Tanouchi A, Sekido R, Kondoh H (2001) Pax6 and Sox2 form a co-DNA-binding partner complex that regulates initiation of lens development. Genes Dev 15:1272-1286. https://doi.org/10.1101/gad. 887101

Kizhatil K, Bennett V (2004) Lateral membrane biogenesis in human bronchial epithelial cells requires 190-kDa ankyrinG. J Biol Chem 279:16706-16714. https://doi.org/10.1074/ jbc.M314296200

Kizhatil K, Davis JQ, Davis L, Hoffman J, Hogan BL, Bennett V (2007) Ankyrin-G is a molecular partner of E-cadherin in epithelial cells and early embryos. J Biol Chem 282:26552-26561. https://doi.org/10.1074/jbc. M703158200

Kondoh H, Kamachi Y (2010) SOX-partner code for cell specification: Regulatory target selection and underlying molecular mechanisms. Int J Biochem Cell B 42:391-399. https://doi.org/10.1016/j.biocel.2009.09.003

Lee JH, Skalnik DG (2005) CpG-binding protein (CXXC finger protein 1) is a component of the mammalian Set1 histone H3Lys4 methyltransferase complex, the analogue of the yeast Set1/COMPASS complex. J Biol Chem 280:41725-41731. https://doi.org/10.1074/jbc.M508312200

Liu K et al (2013) The multiple roles for Sox 2 in stem cell maintenance and tumorigenesis. Cell Signal 25:1264-1271. https://doi.org/10.1016/j.cellsig.2013.02. 013

Masui S et al (2007) Pluripotency governed by Sox2 via regulation of Oct $3 / 4$ expression in mouse embryonic stem cells. Nat Cell Biol 9:625-635

Merrill BJ, Gat U, DasGupta R, Fuchs E (2001) Tcf3 and Lef1 regulate lineage differentiation of multipotent stem cells in skin. Genes Dev 15:1688-1705. https://doi.org/10.1101/ $\operatorname{gad} .891401$

Merrill BJ, Pasolli HA, Polak L, Rendl M, Garcia-Garcia MJ, Anderson KV, Fuchs E (2004) Tcf3: a transcriptional regulator of axis induction in the early embryo. Development 131:263-274. https://doi.org/10.1242/dev.00935

Nguyen H, Rendl M, Fuchs E (2006) Tcf3 governs stem cell features and represses cell fate determination in skin. Cell 127:171-183 
Ochieng JK et al (2014) Sox2 regulates the emergence of lung basal cells by directly activating the transcription of Trp63. Am J Respir Cell Mol Biol. https://doi.org/10.1165/rcmb. 2013-0419oc

Papanayotou C et al (2008) A mechanism regulating the onset of Sox 2 expression in the embryonic neural plate. PLoS Biol 6:e2

Pereira L, Yi F, Merrill BJ (2006) Repression of Nanog gene transcription by Tcf3 limits embryonic stem cell self-renewal. Mol Cell Biol 26:7479-7491. https://doi.org/10. 1128/MCB.00368-06

Pevny L, Placzek M (2005) SOX genes and neural progenitor identity. Curr Opin Neurobiol 15:7-13

Que J, Luo X, Schwartz RJ, Hogan BL (2009) Multiple roles for Sox 2 in the developing and adult mouse trachea. Development 136:1899-1907. https://doi.org/10.1242/dev. 034629

Ruggero D et al (2003) Dyskeratosis congenita and cancer in mice deficient in ribosomal RNA modification. Science 299:259-262. https://doi.org/10.1126/science.1079447

Schlosser G, Ahrens K (2004) Molecular anatomy of placode development in Xenopus laevis. Dev Biol 271:439-466

Smith ZD, Sindhu C, Meissner A (2016) Molecular features of cellular reprogramming and development. Nat Rev Mol Cell Biol 17:139-154. https://doi.org/10.1038/nrm.2016.6

Sward K, Sadegh MK, Mori M, Erjefalt JS, Rippe C (2013) Elevated pulmonary arterial pressure and altered expression of Ddah1 and Arg1 in mice lacking cavin-1/PTRF. Physiol Rep 1:e00008. https://doi.org/10.1002/phy2.8

Takahashi K, Yamanaka S (2006) Induction of pluripotent stem cells from mouse embryonic and adult fibroblast cultures by defined factors. Cell 126:663-676. https://doi.org/10. 1016/j.cell.2006.07.024

Takahashi K, Tanabe K, Ohnuki M, Narita M, Ichisaka T, Tomoda K, Yamanaka S (2007) Induction of pluripotent stem cells from adult human fibroblasts by defined factors. Cell 131:861-872

Taranova OV, Magness ST, Fagan BM, Wu Y, Surzenko N, Hutton SR, Pevny LH (2006) Sox2 is a dose-dependent regulator of retinal neural progenitor competence. Genes Dev 20:1187-1202

Tompkins DH, Besnard V, Lange AW, Keiser AR, Wert SE, Bruno MD, Whitsett JA (2011) Sox2 activates cell proliferation and differentiation in the respiratory epithelium. Am J Resp Cell Mol 45:101-110. https://doi.org/10.1165/ rcmb.2010-0149oc
Uchikawa M, Ishida Y, Takemoto T, Kamachi Y, Kondoh H (2003) Functional analysis of chicken Sox2 enhancers highlights an array of diverse regulatory elements that are conserved in mammals. Dev Cell 4:509-519

Visel A, Thaller C, Eichele G (2004) GenePaint.org: an atlas of gene expression patterns in the mouse embryo. Nucleic Acids Res 32:D552-D556. https://doi.org/10.1093/nar/ gkh029

Volckaert T, Campbell A, Dill E, Li C, Minoo P, De Langhe S (2013) Localized Fgf10 expression is not required for lung branching morphogenesis but prevents differentiation of epithelial progenitors. Development 140:3731-3742. https://doi.org/10.1242/dev.096560

Wood HB, Episkopou V (1999) Comparative expression of the mouse Sox 1, Sox 2 and Sox 3 genes from pre-gastrulation to early somite stages. Mech Dev 86:197-201

Wu MZ et al (2011) Interplay between HDAC3 and WDR5 is essential for hypoxia-induced epithelial-mesenchymal transition. Mol Cell 43:811-822. https://doi.org/10.1016/j. molcel.2011.07.012

Wu CI, Hoffman JA, Shy BR, Ford EM, Fuchs E, Nguyen H, Merrill BJ (2012) Function of Wnt/beta-catenin in counteracting Tcf3 repression through the Tcf3-beta-catenin interaction. Development 139:2118-2129. https://doi.org/ 10.1242/dev.076067

$\mathrm{Xu} \mathrm{Z}$ et al (2012) Synergistic effect of SRY and its direct target, WDR5, on Sox9 expression. PLoS ONE. https://doi.org/ 10.1371/journal.pone.0034327

$\mathrm{Xu} \mathrm{Y}$ et al (2016) Transcriptional control of somatic cell reprogramming. Trends Cell Biol 26:272-288. https://doi. org/10.1016/j.tcb.2015.12.003

Yamanaka S (2012) Induced pluripotent stem cells: past, present, and future. Cell Stem Cell 10:678-684. https://doi. org/10.1016/j.stem.2012.05.005

Yang Y, Mahaffey CL, Berube N, Frankel WN (2006) Interaction between fidgetin and protein kinase A-anchoring protein AKAP95 is critical for palatogenesis in the mouse. J Biol Chem 281:22352-22359. https://doi.org/10.1074/ jbc.M603626200

Yi F, Pereira L, Hoffman JA, Shy BR, Yuen CM, Liu DR, Merrill BJ (2011) Opposing effects of Tcf3 and Tcf1 control Wnt stimulation of embryonic stem cell self-renewal. Nat Cell Biol 13:762-770. https://doi.org/10.1038/ ncb2283 